\title{
Inducible Clindamycin Resistance in Clinical Isolates of Staphylococcus
} aureus

\author{
Abdolmajid Ghasemian ${ }^{1}$; Shahin Najar Peerayeh ${ }^{1, ;} ;$ Bita Bakhshi $^{1}$; Mohsen Mirzaee ${ }^{1}$ \\ ${ }^{1}$ Department of Bacteriology, Faculty of Medical Sciences, Tarbiat Modares University, Tehran, IR Iran \\ ${ }^{*}$ Corresponding author: Shahin Najar Peerayeh, Department of Bacteriology, Faculty of Medical Sciences, Tarbiat Modares University, Tehran, IR Iran. Tel: +98-92182883870, Fax: +98- \\ 82884555, E-mail: najarp_s@modares.ac.ir
}

Received: November 16, 2013; Accepted: December 10, 2013

\begin{abstract}
Background:Staphylococcus aureus is one of the most important agents causing nosocomial infections. Inducible clindamycin resistance is an important concern, because common laboratory tests could not detect it.

Objectives: The aim of this study was to detect the inducible clindamycin resistance by D-test method.

Materials and Methods: A total of 209 clinical S. aureus isolates were collected and identified by conventional phenotypic tests. Antibiotic susceptibility pattern was detected by disc diffusion method. D-test was done using clindamycin $(2 \mu \mathrm{g})$ and erythromycin $(15 \mu \mathrm{g})$ discs according to the protocols of Clinical and Laboratory Standards Institute (CLSI). To detect methicillin resistant Staphylococcus aureus (MRSA), oxacillin disc was used and the results were confirmed by detection of mecA gene.

Results: Of all 209 clinical S. aureus isolates, 207 (99\%) were resistant to amoxicillin. All isolates were susceptible to vancomycin and linezolid. The rate of clindamycin inducible resistance was $4 \%(n=8)$. This phenotype was not observed in MRSA strains. There was no significant difference between methicillin resistant and susceptible strains. Resistance to clindamycin and erythromycin was higher in MRSA strains. $\mathrm{D}^{+}$phenotype was detected in $1(1 \%)$ of all isolates. Methicillin resistance was detected in $66(32 \%)$ isolates by oxacillin disc and mecA gene was detected by PCR.

Conclusions: In our study, inducible clindamycin resistance rate was 4\%; so it is necessary to conduct D-test regularly by disc diffusion for this bacterium. Resistance to erythromycin, clindamycin, ciprofloxacin and gentamicin was significantly higher in MRSA isolates than methicillin susceptible Staphylococcus aureus (MSSA), although the methicillin resistance prevalence was low.
\end{abstract}

Keywords:Staphylococcus aureus; Methicillin-Resistant Staphylococcus aureus; D-test; Inducible Clindamycin Resistance

\section{Background}

Staphylococcus aureus is one of the most important nosocomial pathogens colonizing on surface and epithelial tisuue (1-3). Methicillin resistant Staphylococcus aureus (MRSA) produces penicillin binding protein 2a (PBP-2a, the enzyme causing resistance against semi-synthetic beta lactam antibiotics), which is encoded by the chromosomal gene, mecA. MRSA isolates are found on the body surface of about $2 \%$ of people and cause more systemic and potentially lethal infections in comparison to the methicillin susceptible (MSSA) clinical isolates. The MRSA prevalence is about $45-55 \%$, according to the previous reports from Iran (4-7), although results may be lower based on the studied area or other related reasons $(8,9)$. MRSA strains may infect people in hospital (HA-MRSA) or the community (CA-MRSA). HA-MRSA isolates have a wide antibiotic resistance $(10,11)$. Clindamycin (a lincosamide) and erythromycin (a macrolide) have efficient antibacterial activities against $S$. aureus strains. Clindamycin is the preferred agent due to its excellent pharmacokinetic properties and good penetration into various tissues (12). Resistance to these antimicrobial agents varies among the countries $(7,12-25)$, which is related to the differences in the use of antibiotics and regional factors. Clindamycin is an efficient antibiotic for MRSA infections that is used as an alternative of vancomycin (14). Inducible resistance to clindamycin is important because the common laboratory tests could not recognize it, and there is a difference between laboratory results and clinical treatment, unless doing D-test. Macrolide resistance is a great concern, and clinically important mechanism in S. aureus and other gram positive bacteria. Clindamycin resistance can be constitutive or inducible. Clindamycin and erythromycin inhibit bacterial growth by preventing the protein synthesis of 50s ribosomal subunit. Moreover, it is used in children pneumonia (due to MRSA) and can inhibit the production of Staphylococcal virulence factors. 
Resistance to these antibiotics occurs by methylation of ribosomal target, causing by erm gene encoded proteins. Another mechanism is through the enzymatic degradation of lincosamide caused by proteins encoded by inuA gene. This alteration in the ribosomal target is called macrolide-lincosamide-streptogramine (MLSB) resistance (15). Methylation of rRNA by induced methylase by erythromycin leads to inducible clindamycin resistance. Only low levels of erythromycin are enough to induce resistance to macrolides.

\section{Objectives}

This study was done to assess the rate of inducible clindamycin resistance.

\section{Materials and Methods}

Clinical isolates collected from September 2011 to January 2012 (6-month-period); 209 S. aureus clinical isolates were collected from patients ( $57 \%$ male and $43 \%$ female) admitted to Loghman Hospital. Samples were taken from trachea, blood, skin lesions, tissue cultures and other origins. The identification tests such as mannitol fermentation on MSA mediume, DNase and tube coagulase and colony morphology was done. For antibiotic susceptibility test, antibiotic discs including vancomycin $(30 \mu \mathrm{g})$, linezolid $(30 \mu \mathrm{g})$, erythromycin $(15 \mu \mathrm{g})$, clindamycin $(2 \mu \mathrm{g})$, tetracycline (30 $\mu \mathrm{g})$, amoxicillin $(10 \mu \mathrm{g})$, oxacillin $(1 \mu \mathrm{g})$, cotrimoxazole (25 $\mu \mathrm{g})$, gentamicin $(10 \mu \mathrm{g})$ and ciprofloxacin $(5 \mu \mathrm{g})$ were used (provided from MAST, UK).After 18-22 hours the results were observed and recorded. S. aureus ATCC25923 was used as control.

Clindamycin inducible resistance (D-test) was carried out using locating clindamycin and erythromycin discs $(10,16,19)$. Antibiogram test was concluded after preparing a 0.5 Mc Farland turbidity of each isolate in sterile saline serum and culturing on Mueller Hinton Agar using the Clinical and Laboratory Standards Institute (CLSI) recommendations. In D-test, induced resistance was observed in isolates resistant to erythromycin (inhibition zone of $14 \mathrm{~mm} \geq$ ) and susceptible to clindamycin (inhibition zone of $21 \mathrm{~mm} \leq$ ) by a D shaped zone, when using the both antibiotics (iMLSB, Figure 1). In the laboratory, the phenomenon can be detected by D-test on Mueller Hinton Agar (MHA) and placing these two antibiotics close to each other (in a 14-22 mm distance) (17).

The following phenotypes were observed during Dtest process:

R: resistant to both (erythromycin and clindamycin), S: sensitive to both mentioned antibiotics, D: induced resistant to clindamycin, $\mathrm{D}$ positive $\left(\mathrm{D}^{+}\right)$: growth of a few colonies in the D-shaped sensitivity zone.

\subsection{PCR Assay}

Primer sequences were as follow: F: GTG AAG ATA TAC CAA GTG ATT and R: ATG CGC TATAGATTGAAA GGA. PCR reaction mixture included: $9.5 \mu \mathrm{L}$ dd water, $2 \mu \mathrm{L}$ dNTPs $(1$
$\mathrm{mM}, 1$ to 10 diluted), $1.5 \mu \mathrm{LgCl}_{2}$ (50 mM, 1 to 10 diluted), $1 \mu \mathrm{L}$ of each primer, $3 \mu \mathrm{L} 10 \mathrm{X}$ buffer, $2 \mu \mathrm{L}$ Taq polymerase (500 U, 1 to 10 diluted) and $5 \mu \mathrm{L}$ DNA template. Thermo cycler conditions comprised a $94^{\circ} \mathrm{C}$ for 5 minutes followed by $55^{\circ} \mathrm{C}$ for 30 seconds, $72^{\circ} \mathrm{C}$ (30 seconds) for 30 cycles and final $72^{\circ} \mathrm{C}$ for 4 minutes and then hold at $4^{\circ} \mathrm{C}$ for 5 minutes (18). The products were visualized under UV Trans illuminator gel, then $5 \lambda$ of mecA product mixed with $2 \lambda$ of both staining dyes (red gel and loading buffer (Sina gen, Iran) were used and then run in each well.

\section{Results}

\subsection{Antibiotic Susceptibility Test}

The samples including trachea $74 \%(n=154)$, blood $14.3 \%$ $(\mathrm{n}=30)$, skin lesions $13 \%(\mathrm{n}=27)$, tissue culture $1.4 \%(\mathrm{n}=3)$ and some other specimens, had shown resistance to the following antibiotics: clindamycin $27 \%(n=57)$, erythromycin $31 \%(n=64)$, cotrimoxazole $11 \%(n=23)$, tetracycline $43 \%(n$ $=90)$, ciprofloxacin $31 \%(n=65)$, gentamicin $19 \%(n=40)$, amoxicillin $99 \%(n=207)$ and oxacillin $32 \%(n=66)$. All of the isolates were susceptible to vancomycin and linezolid. Cotrimoxazole and gentamicin had antimicrobial effects on the clinical isolates, after vancomycin and linezolid.

Antimicrobial resistance in MRSA isolates were as follow: tetracycline $36 \%(\mathrm{n}=24)$, erythromycin $35 \%(\mathrm{n}=$ $23)$, clindamycin $39 \%(n=26)$, ciprofloxacin $36 \%(n=26)$, amoxicillin $90 \%(n=74)$, cotrimoxazole $31 \%(n=21)$, gentamicin $46 \%(n=31)$ and in MSSA were: erythromycin $12 \%(n=25)$, clindamycin $6.66 \%(n=14)$, tetracycline $31.1 \%$ $(\mathrm{n}=65)$, ciprofloxacin $11.11 \%(\mathrm{n}=23)$, amoxicillin $87 \%(\mathrm{n}$ $=182)$, cotrimoxazole $31 \%(n=66)$ and gentamicin $4.4 \%$ $(\mathrm{n}=10)$. There was significant difference in antibiotic resistance to erythromycin, clindamycin, ciprofloxacin and gentamicin between MRSA and MSSA isolates. Excluding the vancomycin and linezolid antibiotics, gentamicin (4.4\%) and clindamycin (6.66\%) were the most effective antibiotics inhibiting MSSA isolates, while cotrimoxazole (31\%) and erythromycin (35\%) have the highest effect on MRSA isolates.

\subsection{D-test}

Susceptibilities to antimicrobial agents detected by Dtest during disc diffusion were as follow:(a). 50\% ( $n=104)$ were susceptible to both clindamycin and erythromycin (S), (b). 15\% $(\mathrm{n}=31)$ were resistant to both mentioned agents $(R),(c) .4 \%(n=8)$ were inducible clindamycin resistant (D) (Figure $2 \mathrm{~A}$ ) and all were MSSA, (d). 1\% (n=3) were inducible positive $\left(D^{+}\right)$(Figure $2 \mathrm{~B}$ ).

\subsection{PCR Assay}

The results to detect mecA gene (MRSA isolates) confirmed the oxacillin disc diffusion. In this study $32 \%$ ( $n=$ 66) of isolates were detected as MRSA by confirmation of mecA gene using PCR assay (Figure 3). 
Ghasemian A et al.

Figure 1. Antibiotic Susceptibility Pattern of Methicillin Resistant and Susceptible Clinical Isolates

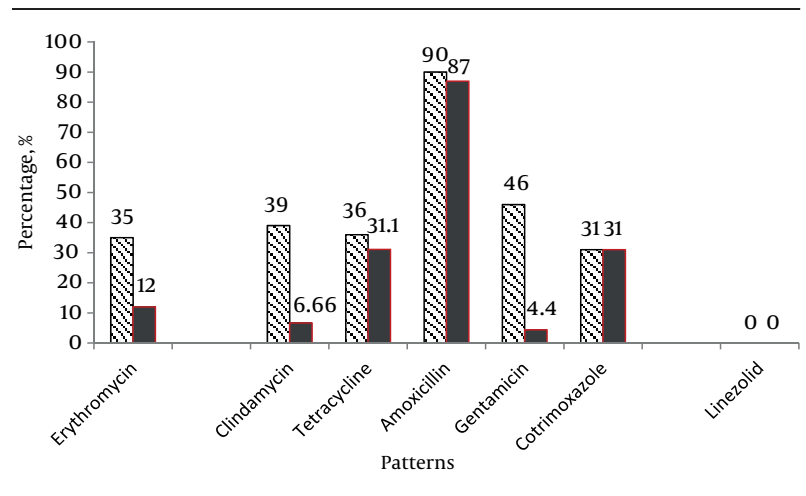

MRSA isolates are shown in bright; and MSSA in red (dark) color.

\section{Figure 2. D-Test}
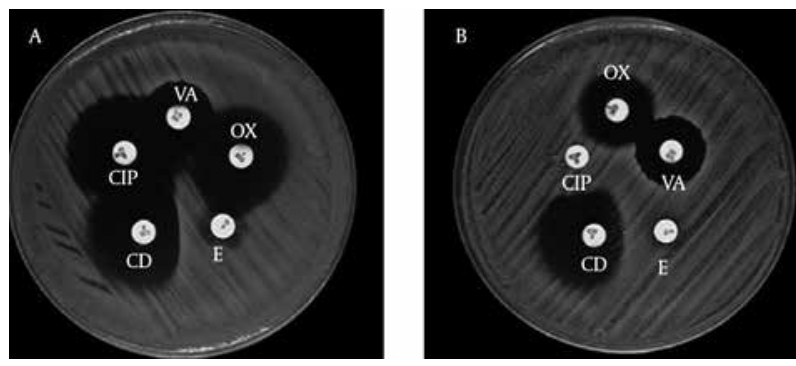

(A): An interfere in susceptibility of clindamycin zone (D-shaped zone) shows the inducible resistance. (B): this isolate has a sub-population and ability to proliferate in D-shaped susceptibility zone ( $\mathrm{D}^{+}$phenotype).

Figure 3. Electrophoresis of mecA Gene PCR Amplicon

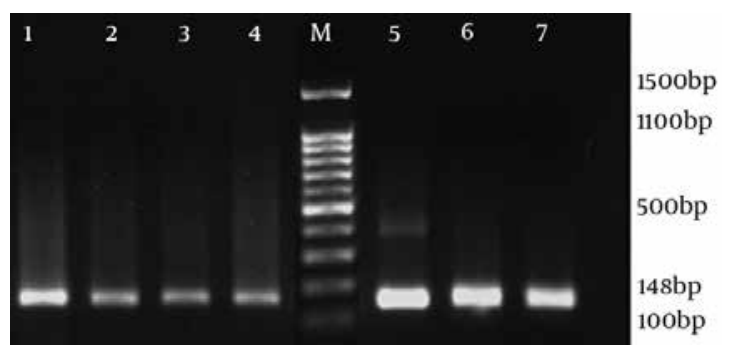

M: marker, Column 5: positive control.

\section{Discussion}

Inducible resistance to Macrolide-Lincosamide and Streptogramin(iMLSB), especially to clindamycin in S. aureus is a very important concern as these antibiotics are among the few restricted effective agents $(19,20)$. The resistance to macrolides can be mediated by msrA gene encoding efflux proteins or via erm gene encoding enzymes that confer inducible or constitutive resistance to MLS $B$ antibiotics. Clindamycin is an excellent effective drug particularly for the treatment of Staphylococcal skin and soft tissue infections and as an alternative in penicillin-allergic patients, which has yet good oral bioavailability (15). Methicillin resistant isolates have a greater widespread antibiotic resistance. Inducible resistance could not be detected, unless doing D-test with the both clindamycin and erythromycin disks. Therefore, D-test is an imperative part of routine antimicrobial susceptibility test for all clinical isolates of S. aureus. Strains with this character are resistant to macrolides (erythromycin) and susceptible to clindamycin. In this study inducible resistance was seen in eight isolates (4\%) and D positive in three isolates (1\%), which were methicillin susceptible. $\mathrm{D}$ and $\mathrm{D}^{+}$inducible resistance have the same outcome in patient, however the causing genes differ. There are various reports of inducible resistance, in Vivian study, among 81 erythromycin resistant isolates, 10 were susceptible to clindamycin and $6.2 \%$ of them had inducible resistance (21). In a report, $10 \%$ of the isolates were inducible resistant and the incidence of $\mathrm{R}$ and $\mathrm{S}$ phenotypes were $9 \%$ and $8 \%$, respectively; and MRSA strains had higher antibiotic resistance (14). Deotale et al. detected that $14 \%$ of the isolates had inducible resistance, which was more prevalent among MSSA isolates (20). Other reports of inducible resistance to clindamycin are as follow: Sedighi found that $5 \%$ of CA-MRSA and $6.3 \%$ of HA-MRSA isolates had inducible clindamycin resistant (D-test) (22), and Rahbar et al. stated that inducible resistance was 9.7\% (23), while reported phenotypes in studies from other countries are variable, especially from India (17, 24-27). In this study all of erythromycinresistant and clindamycin-susceptible isolates showed inducible resistance. None of methicillin-resistant clinical isolates showed inducible resistance to clindamycin, but had higher resistance to both erythromycin and clindamycin; some of the reports indicated that MRSA isolates were more capable to resist against clindamycin and other antibiotics (28-31) and these results are in alignment with our study. Fortunately, inducible resistance was low in comparison to the other countries, but the laboratories should survey the probability of inducible resistance besides antibiotic susceptibility testing, because the resistance to these antibiotics increases by more consumption during the time. In this study, 20 (9.56\%) of MRSA isolates were resistant to all of the antibiotics, except vancomycin and linezolid, while gentamycin (19\%) and co-trimoxazole (11\%) were more effective compared to the other antibiotics.

This study showed inducible resistance and other phenotypes in Loghman Hospital of Tehran, Iran. In this study, inducible resistance to clindamycin was low; it should be detected by D-test because of the important effects of clindamycin.

\section{Acknowledgements}

The authors would appreciate the cooperation from Loghman Hospital of Tehran in the collection of clinical isolates. 


\section{Authors' Contributions}

Abdolmajid Ghasemian performed the laboratory work. Najar Peerayeh inspected and guided the study. Dr. Bakhshi was the supervisor of this study. Mohsen Mirzaee was co-worker and helped in data analyzing.

\section{Financial Disclosure}

The authors declared that they had no conflict of interest and will not.

\section{Funding/Support}

This study was supported by a grant from Tarbiat Modares University, Faculty of Medical Sciences, Tehran, Iran.

\section{References}

1. Zmantar T, Kouidhi B, Miladi H, Mahdouani K, Bakhrouf A. A microtiter plate assay for Staphylococcus aureus biofilm quantification at various $\mathrm{pH}$ levels and hydrogen peroxide supplementation. New Microbiol. 2010;33(2):137-45.

2. Weidenmaier C, Goerke C, Wolz C. Staphylococcus aureus determinants for nasal colonization. Trends Microbiol. 2012;20(5):243-50.

3. Ajao AO, Harris AD, Roghmann MC, Johnson JK, Zhan M, McGregor JC, et al. Systematic review of measurement and adjustment for colonization pressure in studies of methicillin-resistant Staphylococcus aureus, vancomycin-resistant enterococci, and clostridium difficile acquisition. Infect Control Hosp Epidemiol. 2011;32(5):481-9.

4. Askari E, Soleymani F, Arianpoor A, Tabatabai SM, Amini A, Naderinasab M. Epidemiology of mecA-Methicillin Resistant Staphylococcus aureus (MRSA) in Iran: A Systematic Review and Metaanalysis. Iran J Basic Med Sci. 2012;15(5):1010-9.

5. Azimian A, Najar-Pirayeh S, Mirab-Samiee S, Naderi M. Occurrence of methicillin resistant Staphylococcus aureus (MRSA) among clinical samples in tehran-iran and its correlation with polymorphism of specific accessory gene regulator (AGR) groups. Braz J Microbiol. 2012;43(2):779-85.

6. Ekrami A, Samarbafzadeh A, Alavi M, Kalantar E, Hamzeloi F. Prevalence of methicillin resistant Staphylococcus species isolated from burn patients in a burn center, Ahvaz, Iran . Jundishapur Microbiol. 2010;3(2):84-91.

7. Saderi H, Owlia P, Eslami M. Prevalence of Macrolide - Lincosamide- Streptogramin B (MLSB) resistance in S. aureus isolated from patients in Tehran, Iran. Ir J Pathol. 2009;4(4):161-6.

8. Rahimi F, Bouzari M, Katouli M, Pourshafie M. Prophage Typing of Methicillin Resistant Staphylococcus aureus Isolated from a Tertiary Care Hospital in Tehran, Iran. Jundishapur J Microbiol. 2012;6(1):80-5.

9. Mohajeri P, Izadi B, Rezaei M, Farahani A. Frequency Distribution of Hospital-Acquired MRSA Nasal Carriage Among Hospitalized Patients in West of Iran. Jundishapur J Microbiol. 2013;6(6).

10. Pallab R, Vikas G, Rachna S. Methicillin-resistant Staphylococcus aureus (MRSA) in developing and developed countries: implications and solutions. Reg Health F. 2011;15(1):74-82.

11. Knight GM, Budd EL, Whitney L, Thornley A, Al-Ghusein H, Planche T, et al. Shift in dominant hospital-associated methicillin-resistant Staphylococcus aureus (HA-MRSA) clones over time. J Antimicrob Chemother. 2012;67(10):2514-22.
12. Dardi CK, Khare AS. Inducible clindamycin resistance in Staphylococcus aureus in a tertiary care rural hospital. Indian J Basic $\mathcal{C}$ Applied Med Res. 2013;7(2):686-93.

13. Mohammad A. Incidence of macrolide-lincosamide-streptogramin-B resistance phenotypes of methicillin resistance Staphylococcus aureus and methicillin sensitive Staphylococcus aureus among animals in Saudi Arabia . Res J Microbiol. 2012;7:256-62.

14. James SL, James HJ. Inducible clindamycin resistance in staphylococci. Should clinicians and microbiologists be concerned? Antimicrob resist. 2005;40:280-5.

15. Cetin ES, Gunes H, Kaya S, Aridogan BC, Demirci M. Macrolidelincosamide-streptogramin $B$ resistance phenotypes in clinica staphylococcal isolates. Int J Antimicrob Agents. 2008;31(4):364-8.

16. Tiwari HK, Das AK, Sapkota D, Sivrajan K, Pahwa VK. Methicillin resistant Staphylococcus aureus: prevalence and antibiogram in a tertiary care hospital in western Nepal. J Infect Dev Ctries. 2009;3(9):681-4

17. Yilmaz G, Aydin K, Iskender S, Caylan R, Koksal I. Detection and prevalence of inducible clindamycin resistance in staphylococci. J Med Microbiol. 2007;56(Pt 3):342-5.

18. Gey A, Werckenthin C, Poppert S, Straubinger RK. Identification of pathogens in mastitis milk samples with fluorescent in situ hybridization. J Vet Diagn Invest. 2013;25(3):386-94.

19. Prabhu K, Rao S, Rao V. Inducible Clindamycin Resistance in Staphylococcus aureus Isolated from Clinical Samples. J Lab Physicians. 2011;3(1):25-7.

20. Deotale V, Mendiratta DK, Raut U, Narang P. Inducible clindamycin resistance in Staphylococcus aureus isolated from clinical samples. Indian J Med Microbiol. 2010;28(2):124-6.

21. Coutinho VLS, Paiva RM, Reiter KC, de-Paris F, Barth AL, Machado ABMP. Distribution of erm genes and low prevalence of inducible resistance to clindamycin among staphylococci isolates. Braz JInfect Dis. 2010;14(6):564-8.

22. Sedighi I, Yousefi MR, Pak N. D test method for detection of inducible clindamycin resistance in Staphylococcus aureus. Iranian J Pediatr. 2009;19(3):293-7.

23. Rahbar M, Hajia M. Inducible Clindamycin Resistance in Staphylococcus aureus:A Cross-Sectional Report. Pak J Biol Sci. 2007;10(1):189-92.

24. Jadhav SV, Gandham NR, Sharma MKM. Prevalence of inducible clindamycin resistance among community-and hospital-associated Staphylococcus aureus isolates in a tertiary care hospital in India. Biomed Res. 2011;22(4):465-9.

25. Gadepalli R, Dhawan B, Mohanty S, Kapil A, Das BK, Chaudhry R Inducible clindamycin resistance in clinical isolates of Staphylococcus aureus. Indian J Med Res. 2006;123(4):571-3.

26. Shantala GB, Shetty AS, Rao RKV. Detection of inducible Clindamycin resistance in clinical isolates of Staphylococcus aureus by the disc diffusion induction test. J Clin Diagnost Res. 2011;5(1):35-7.

27. Debdas D, Joshi S. Incidence of clindamycin resistance in clinical isolates of Staphylococcus aureus. J Infect Dev Ctries. 2011;5(4):316-7.

28. Morris DO, Mauldin EA, O'Shea K, Shofer FS, Rankin SC. Clinical, microbiological, and molecular characterization of methicillinresistant Staphylococcus aureus infections of cats. Am J Vet Res 2006;67(8):1421-5.

29. de Moura JP, Pimenta FC, Hayashida M, Cruz ED, Canini SR, Gir E. Colonization of nursing professionals by Staphylococcus aureus. Rev Lat Am Enfermagem. 2011;19(2):325-31.

30. Arora S, Devi P, Arora U, Devi B. Prevalence of Methicillin-resistant Staphylococcus Aureus (MRSA) in a Tertiary Care Hospital in Northern India. J Lab Physicians. 2010;2(2):78-81.

31. Sachin S. The prevalence, antibiogram and characterisationo methicillin resistant Staphylococcus aureus among the patients from the Doon Valley hospitals. AFR J MICROBIOL RES. 2011;5(21). 